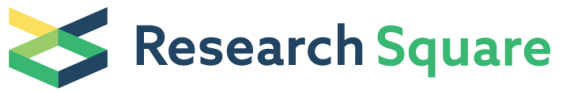

\section{Childhood Disability in Rural Niger: A Population-based Assessment Using the Key Informant Method}

\section{Lena Morgon Banks ( $\nabla$ morgon.banks@lshtm.ac.uk)}

London School of Hygiene \& Tropical Medicine

Jing Liu

Fafo

Anne Kielland

Fafo

\section{Ali Bako Tahirou}

Laboratoire d'Études et de Recherche sur les Dynamiques Sociales et le Développement Local (LASDEL)

Abdoul Karim Seydou Harouna

Laboratoire d'Études et de Recherche sur les Dynamiques Sociales et le Développement Local (LASDEL)

Islay Mactaggart

London School of Hygiene \& Tropical Medicine

\section{Ragnhild Dybdahl}

OsloMet - Oslo Metropolitan University

\section{Dan Firoun Mounkaila}

Fédération Nigérienne des Personnes Handicapées, Niamey, Niger

\section{Arne Grønningsaeter}

Fafo

\section{Research Article}

Keywords: childhood disability, planning health, education and other services, paediatricians

Posted Date: May 25th, 2021

DOI: https://doi.org/10.21203/rs.3.rs-512776/v1

License: (c) (i) This work is licensed under a Creative Commons Attribution 4.0 International License. Read Full License

Version of Record: A version of this preprint was published at BMC Pediatrics on March 31st, 2022. See the published version at https://doi.org/10.1186/s12887-022-03226-0. 


\section{Abstract}

Background: Data on childhood disability is essential for planning health, education and other services. However, information is lacking in many low- and middle-income countries, including Niger. This study uses the Key Informant Method, an innovative and cost-effective strategy for generation population-based estimates of childhood disability, to estimate the prevalence and causes of moderate/severe impairments and disabling health conditions in children of school-going age (7-16 years) in the Kollo department of western Niger.

Methods: Community-based key informants were trained to identify children who were suspected of having the impairment types/health conditions included in this study. Children identified by key informants were visited by paediatricians and underwent an assessment for moderate/severe vision, hearing, physical and intellectual impairments, as well as epilepsy, albinism and emotional distress.

Results: 2,561 children were identified by key informants, of whom 2191 were visited by paediatricians (response rate $=85.6 \%$ ). Overall, 597 children were determined to have an impairment/health condition, giving a prevalence of disability of 11.4 per 1000 children (10.6-12.2). Intellectual impairment was most common (4.9 per 1000), followed by physical (4.9 per 1000) and hearing impairments (4.7 per 1000). Many children had never sought medical attention for their impairment/health condition, with health seeking ranging from $40.0 \%$ of children with visual impairment to $67.2 \%$ for children with physical impairments.

Conclusion: The Key Informant Method enabled the identification of a large number of children with disabling impairments and health conditions in rural Niger, many of whom have unmet needs for health and other services.

\section{Introduction}

Robust estimates on the prevalence of childhood disability are lacking, particularly in low- and middle-income countries [1]. It is widely reported that $5 \%$ of children globally are living with moderate to severe disabilities [2]. However, the data underlying this estimate stems from "inconsistent, fragmented and partial data" arising from the 2004 Global Burden of Disease update [1, 3].

Disability is defined by the United Nations Convention on the Rights of Persons with Disabilities (UNCRPD) as including "those who have long-term physical, mental, intellectual or sensory impairments which in interaction with various barriers may hinder their full and effective participation in society on an equal basis with others" [4]. Closely linked to this definition is the International Classification of Functioning, Disability and Health's (ICF) model of disability. Under the ICF, individuals can have a health condition that causes an impairment in one or more body structures or functions [5]. Impairments in turn can lead to activity limitations (e.g. difficulty walking, remembering) or participation restrictions (e.g. going to school, work), depending on their interaction with personal or environmental contextual factors (e.g. their access to assistive devices, social attitudes towards disability, accessibility of infrastructure and communication) [5]. For example, two children may have the same level of visual impairment, but different levels of functioning and participation based on if they have access to glasses or other assistive devices and the extent to which their environment is disability-inclusive (e.g. inclusive education options are available and affordable, attitudes about disability in their family and community).

Good quality data on childhood impairments and disability is needed to inform national and sub-national policy and planning. For example, data on the prevalence of disability and impairments are essential for designing and budgeting for health services, inclusive education and community-based programmes. The importance of data on 
disability is increasingly recognised in national and international commitments. For example, Article 31 of the UNCRPD obliges the 164 signatory States to collect data on disability to monitor and formulate appropriate policies to support the implementation of the UNCRPD [6]. Further, the 2030 Sustainable Development Goals (SDGs) calls for the collection of data on disability for disaggregation of all goals and indicators by disability status to ensure its mandate of "no one left behind" from development progress [7].

The Key Informant Method (KIM) is an innovative strategy for identifying relatively rare groups (e.g. children with disabilities, but has been used for other groups such as sex workers and people living with HIV) and generating population-level data on childhood disability [8]. The KIM has been used to identify children with sensory, physical and intellectual impairments and epilepsy in settings such as Malawi [8], Kenya [9], India [10] and Bangladesh [11]. The KIM trains community-based volunteers to identify children with potentially disabling impairments, who are then examined by medical professionals. The KIM is considered valid and cost-effective compared to other methods for estimating prevalence of impairments in children [8]. For example, a study in Bangladesh estimated that the KIM cost $£ 90$ per child identified with an impairment, compared to $£ 352$ per child for a population-based survey in the same setting [11].

This study uses the KIM to estimate the prevalence of disability in children of school-going age (7-16 years) in the Kollo department of the Tillabéri region of west Niger. Niger is a low-income country, which ranks at the bottom of the Human Development Index [12, 13]. Previous estimates of disability prevalence from the 2012 census indicate that $3.7 \%$ of boys and $3.8 \%$ of girls have a disability [14]. However, this figure uses only a single question on disability, which is not recommended for providing robust prevalence estimates [15]. Further, data on clinical impairments and aetiology is important for informing the provision of services.

\section{Methods}

Study setting and population

This study was conducted in the Kollo department of the Tillabéri region of west Niger between September 2018March 2019. Five predominantly rural communes in this department were selected: Kouré, N'Dounga, Kirtachi, Hamdallaye and Diantchandou.

This study was embedded within a larger project on access to education for children with disabilities in the Sahel. Consequently, this study focused on children ages 7-16 years, to reflect the standard school-going ages for Niger (primary and lower secondary). The underlying population in our study area was estimated at 68,844 children ages 7-16 years, based on the 2012 census and updated to reflect population growth.

Data collection

Each of the five communes had a Commune Facilitator who was responsible for coordinating with village chiefs to select Key Informants (KIs). In total, 185 villages (and surrounding areas) were identified, each of which was assigned a KI to identity children with specified impairments and health conditions. Kls were selected based on their familiarity with and acceptance in their designated village. KIs also required sufficient literacy skills to complete listing forms of identified children. The Kls and Commune Facilitators attended a one-day training workshop in September 2018 which covered: background and sensitisation on disability, the identification of specific impairments and health conditions relevant to this study, methods for case finding and procedures for listing children. In the two months following training, Kls identified and listed children suspected to have the 
impairments and health conditions specified in the training. The specified impairments and health conditions were visual, hearing, physical and intellectual impairments, as well as epilepsy, albinism and emotional distress.

Six paediatricians then visited the children listed by KIs to provide an assessment of disability. Paediatricians received a five-day training on study protocols, including the use of mobile applications used for clinical screening (e.g. PeekAcuity for visual acuity, HearTest for auditory). Previous KIM studies have invited children identified by KIs to attend screening camps where they are examined by health professionals. However, non-attendance rates have been high in previous studies (e.g. $48 \%$ in Malawi, $52 \%$ in Bangladesh) due to accessibility, financial and informational challenges $[8,16]$. Consequently, doctors visited children in their homes or other local meeting point to minimise attrition.

\section{Disability Assessment}

Children identified by KIs as having potentially disabling impairments underwent an assessment of disability, which involved two stages. In the first stage, guardians and/or children answered questions from the Washington Group-UNICEF module on Child Functioning (ages 5-17) [17]. The Washington Group-UNICEF module asks about the child's level of difficulty in performing everyday activities. Most questions have four possible responses: no difficulty, some difficulty, a lot of difficulty or cannot do. Additional questions on whether the child had albinism or had experienced seizures were also added to the initial screening. These health conditions were added based on feedback from Disabled People's Organisations (DPO) in Niger on local conceptualisations of disability and from similar KIM studies, which found these health conditions are often disabling [8]. Children aged 10 years and older self-reported on their level of functioning, while the primary guardian answered on behalf of children younger than 10 years, and for children with severe difficulties understanding/communicating.

In the second stage, doctors conducted relevant clinical assessments based on the child's answers to the Washington Group-UNICEF screening questionnaire. The mapping of Washington Group-UNICEF screening questions to clinical assessment domains, as well as the cut-offs for determining the presence of a clinical impairment/disabling health condition are described in Table 1.

This assessment of disability combines information on both the child's functioning (Washington Group-UNICEF module) and on clinical impairments (paediatrician assessment). This combination reflects a definition of disability that is more in line with the UNCRPD and the ICF, which views disability as arising from restrictions in functioning and participation due to the interaction of a clinical impairment with personal and environmental barriers $[4,18]$. 
Table 1

Clinical assessment method and definitions of impairment

\begin{tabular}{|c|c|c|c|c|}
\hline $\begin{array}{l}\text { Impairment/health } \\
\text { condition }\end{array}$ & $\begin{array}{l}\text { Washington Group screening } \\
\text { triggers }\end{array}$ & Screen/Exam & Assessment & $\begin{array}{l}\text { Case } \\
\text { definition }\end{array}$ \\
\hline $\begin{array}{l}\text { Moderate/severe } \\
\text { vision impairment }\end{array}$ & $\begin{array}{l}\text { At least some difficulty seeing } \\
\text { (with glasses if used), learning }\end{array}$ & Exam & $\begin{array}{l}\text { Visual acuity } \\
\text { test using } \\
\text { PeekAcuity. Eye } \\
\text { exam with direct } \\
\text { ophthalmoscope } \\
\text { by paediatrician }\end{array}$ & $\begin{array}{l}\log M a r \geq \\
0.5 \text { for both } \\
\text { eyes }\end{array}$ \\
\hline $\begin{array}{l}\text { Moderate/severe } \\
\text { hearing } \\
\text { impairment }\end{array}$ & $\begin{array}{l}\text { At least some difficulty hearing } \\
\text { (with hearing aids if used), being } \\
\text { understood by people inside or } \\
\text { outside of the household, learning }\end{array}$ & Exam & $\begin{array}{l}\text { Pure Tone } \\
\text { Audiometry } \\
\text { (PTA) using } \\
\text { HearTest; ear } \\
\text { exam by } \\
\text { paediatrician } \\
\text { using an } \\
\text { otoscope }\end{array}$ & $\begin{array}{l}\geq 31 \mathrm{~dB} \text { for } \\
\text { both ears }\end{array}$ \\
\hline $\begin{array}{l}\text { Moderate/severe } \\
\text { physical } \\
\text { impairment }\end{array}$ & $\begin{array}{l}\text { At least some difficulty walking } \\
100 \mathrm{~m} \text { or } 500 \mathrm{~m} \text {, with equipment if } \\
\text { used, with self-care, being } \\
\text { understood by people inside or } \\
\text { outside of the household, }\end{array}$ & Exam & $\begin{array}{l}\text { Standardised } \\
\text { observation of } \\
\text { activities (ability } \\
\text { to hold and } \\
\text { change position, } \\
\text { mobility, and } \\
\text { hand function) }\end{array}$ & $\begin{array}{l}\text { Cannot do } \\
\text { at least one } \\
\text { activity, with } \\
\text { functional } \\
\text { difficulty } \\
\text { reported to } \\
\text { have lasted } \\
\text { at least one } \\
\text { month }\end{array}$ \\
\hline Epilepsy & $\begin{array}{l}\text { (Non-Washington group): Child has } \\
\text { ever had a seizure }\end{array}$ & Screen & $\begin{array}{l}\text { Four screening } \\
\text { questions on } \\
\text { type and } \\
\text { frequency of } \\
\text { epilepsy } \\
\text { episodes in the } \\
\text { last year }\end{array}$ & $\begin{array}{l}\text { Reported } \\
\text { three or } \\
\text { more } \\
\text { seizures in } \\
\text { the last year }\end{array}$ \\
\hline Albinism & $\begin{array}{l}\text { (Non-Washington Group): caregiver } \\
\text { report/visual confirmation }\end{array}$ & $\mathrm{n} / \mathrm{a}$ & $\mathrm{n} / \mathrm{a}$ & $\begin{array}{l}\text { Caregiver } \\
\text { report, visual } \\
\text { confirmation }\end{array}$ \\
\hline $\begin{array}{l}\text { Intellectual } \\
\text { impairment }\end{array}$ & $\begin{array}{l}\text { At least some difficulty with self- } \\
\text { care, being understood by people } \\
\text { inside or outside of the household, } \\
\text { learning, remembering, } \\
\text { concentrating on an enjoyed } \\
\text { activity, accepting changes to } \\
\text { his/her routine, controlling his/her } \\
\text { behaviour, making friends }\end{array}$ & Screen & $\begin{array}{l}12 \text { age-relevant } \\
\text { questions on } \\
\text { communication, } \\
\text { behaviour, } \\
\text { comprehension, } \\
\text { concentration, } \\
\text { relationships } \\
\text { and learning }\end{array}$ & $\begin{array}{l}\text { Screens } \\
\text { positive on } \\
\text { at least } 3 \\
\text { questions }\end{array}$ \\
\hline
\end{tabular}

aThis question set was developed and used in a KIM in Malawi [8] and was reviewed for relevance to Niger by Nigerien paediatricians. 


\begin{tabular}{|c|c|c|c|c|}
\hline $\begin{array}{l}\text { Impairment/health } \\
\text { condition }\end{array}$ & $\begin{array}{l}\text { Washington Group screening } \\
\text { triggers }\end{array}$ & Screen/Exam & Assessment & $\begin{array}{l}\text { Case } \\
\text { definition }\end{array}$ \\
\hline Emotional distress & $\begin{array}{l}\text { At least some difficulty being } \\
\text { understood by people inside or } \\
\text { outside of the household, learning, } \\
\text { remembering, concentrating on an } \\
\text { enjoyed activity, accepting } \\
\text { changes to his/her routine, } \\
\text { controlling his/her behaviour, } \\
\text { making friends; seems anxious, } \\
\text { nervous or worried daily or weekly; } \\
\text { seems sad or depressed daily or } \\
\text { weekly }\end{array}$ & Screen & $\begin{array}{l}\text { PHQ-A } \\
\text { (depression) [19] } \\
\text { CRIES-8 (PTSD) } \\
{[20,21]}\end{array}$ & $\begin{array}{l}\text { Depression } \\
(P H Q-A): \\
\text { score } \geq 10 \\
\text { PTSD: score } \\
\text { of } \geq 17\end{array}$ \\
\hline
\end{tabular}

Finally, caregivers of children who were found to have a clinical impairment were asked questions about the attributed cause of the impairment and health-seeking behaviour.

\section{Data analysis}

Data was analysed using R 3.5.3. The denominator for overall and impairment-specific prevalence estimates is the total number of children (7-16 years) living in the study area $(n=68,844)$. This figure was calculated using data from the 2012 census, which was adjusted to reflect population growth using United Nations Population Projections and data from the Niger Bureau of Statistics [22-24]. Overall and impairment-specific prevalence estimates were also adjusted to account for non-response in children identified by Kls, by assuming that prevalence (both overall and by impairment type) was the same as in children who were successfully followed up by paediatricians and able to complete the relevant clinical assessments. Further, one village in the sampled area was used as a pilot, and so prevalence was similarly adjusted assuming the same proportion as in the rest of the study areas. Finally, some children who were followed up by paediatricians were unable to complete all relevant assessments (e.g. for hearing, vision), and so prevalence was adjusted to reflect the prevalence of impairments in children who did complete the assessments and screened positive to similar Washington Group questions triggering the uncompleted assessment.

Sensitivity analysis was performed by varying the overall and impairment-specific prevalence in non-response and pilot children by $\pm 10 \%$ of the prevalence in children followed up, which has been used in other studies $[8,25]$. All prevalence figures include $95 \%$ confidence intervals (95\% Cls).

Ethical considerations

The study received ethical approval from the Comité National Éthique pour la Recherche en Santé [National Ethics Committee for Health Research] in Niger. The study was also registered with the Norwegian Centre for Research Data, which assessed that the processing of personal data in this project is in accordance with data protection legislation. The study purpose and procedures were explained to children and their guardians prior to starting any assessments. Informed consent was obtained from the guardians of all participating children, as they were all below the national age of consent (18 years). However, children provided their assent to participate. Children with unmet health needs were referred for further services by the examining clinician where possible. Respondents were not provided with any remuneration (in cash or kind) for their participation. 


\section{Results}

In total, 2,561 children were listed by KIs as potentially having an impairment, of whom 2,191 were visited by the paediatricians (response rate: 85.6\%) (Fig. 1). Of the 2,191 children followed-up, 1,154 (47.3\%) were eligible for this study and screened for disability. The main reasons children were ineligible were being outside the study age range, or their presenting concern was non-disabling (e.g. skin rash). The 1154 children were first screened using the Washington Group questions, of whom 836 (72.4\%) scored positive in at least one domain (16.0/1000, 95\% Cl: 15.1-16.9) and were eligible for further clinical assessment. Of the 836 children clinically assessed, 597 (71.4\%) met the study definition of disability.

Prevalence of disability and specific impairments/health conditions

Overall, 597 children met the study definition of disability, giving an estimated prevalence in the study area of 11.4 children per 1000 (95\% Cl: 10.6-12.2) (Table 2). The most common impairment type/health condition was intellectual impairments (6.5/1000, 95\% Cl: 5.9-7.1), followed by physical (4.9/1000, 95\% Cl: 4.4-5.4) and hearing $(4.7 / 1000,95 \% \mathrm{Cl}: 4.2-5.2)$ impairments. Almost half of children with a disability had multiple impairments (4.5/1000, 95\% Cl: 4.0-5.0). Prevalence of disability was higher for boys (12.9/1000, 95\% Cl: 11.7-14.1) compared to girls $(9.9 / 1000,95 \% \mathrm{Cl}: 8.9-10.9)$.

These figures are based on the assumption that non-responders (i.e. children listed by KIs but not seen by paediatricians) and children in the pilot village had the same prevalence of disability and specific impairments/health conditions as children who were followed-up and assessed. Sensitivity analyses varied the prevalence in non-responders/pilot village children by $\pm 10 \%$ of prevalence in children followed-up, which gave similar estimates of prevalence as with the original assumption of no difference in prevalence. 
Table 2

Prevalence estimates of impairments/health conditions in children in the study area

\begin{tabular}{|c|c|c|c|}
\hline Impairment/health condition & Number & $\begin{array}{l}\text { Prevalence per } 1000(95 \% \\
\mathrm{Cl}^{\mathrm{a}}\end{array}$ & $\begin{array}{l}\text { Prevalence per } 1000 \\
\text { range }^{b}\end{array}$ \\
\hline $\begin{array}{l}\text { Disability (any impairment/health } \\
\text { condition) }\end{array}$ & 597 & $11.4(10.6-12.2)$ & $11.2-11.7$ \\
\hline Physical impairment & 253 & $4.9(4.4-5.4)$ & $4.7-5,0$ \\
\hline Hearing impairment & 133 & $4.7(4.2-5.2)$ & $4.6-4.8$ \\
\hline Visual impairment & 45 & $1.2(0.9-1.5)$ & $1.2-1.2$ \\
\hline Intellectual impairment & 338 & $6.5(5.9-7.1)$ & $6.3-6.6$ \\
\hline PTSD/Emotional distress & 31 & $0.6(0.4-0.8)$ & $0.6-0.6$ \\
\hline Epilepsy & 100 & $1.9(1.6-2.2)$ & $1.9-2,0$ \\
\hline Albinism & 7 & $0.1(0.0-0.2)$ & $0.1-0.1$ \\
\hline Multiple & 236 & $4.5(4.0-5.0)$ & $4.4-4.6$ \\
\hline \multicolumn{4}{|c|}{$\begin{array}{l}\text { aBased on assumption that prevalence of disability and impairments/health conditions was the same in } \\
\text { children in the pilot village and in non-responders (overall and for specific screens) }\end{array}$} \\
\hline
\end{tabular}

Physical impairments

Overall, 518 diagnoses were provided for the 253 children with physical impairments (Table S1). A neurological diagnosis was most common $(n=206,39.8 \%)$, followed by congenital $(n=184,35.5 \%)$, acquired non-traumatic $(n$ $=90,17.4 \%)$ and traumatic $(n=38,7.3 \%)$. The most common diagnoses listed by paediatricians were of cerebral palsy $(n=26)$, unspecified developmental delay $(n=33)$, hemiplegia $(n=32)$ and epilepsy $(n=61)$. For $73(14.1 \%)$ instances, the paediatricians were unable to provide a specific diagnosis of a health condition.

Hearing impairments

In total, 133 children (4.7 per 1000, 95\% Cl: $4.2-5.2)$ had bilateral hearing impairments. Most children identified had a profound hearing impairment $(81+\mathrm{dB} ; 66.2 \%)$ (Table 3$)$. The most common diagnoses were sensorineural congenital (32.3\%), sensorineural acquired $(25.6 \%)$ and serous otitis media (4.5\%). Paediatricians were unable to provide a diagnosis for $16.5 \%$ of cases.

The Washington Group screening triggered a hearing assessment for 453 children, which was completed by only 231 children. Children who did not complete the hearing assessment often had intellectual impairments $(n=202$, $91 \%$ of non-completed). 
Table 3

Severity and causes of hearing impairment

\begin{tabular}{|lll|}
\hline Severity & \# of children & $\%$ \\
\hline Moderate $(31-60 \mathrm{~dB})$ & 29 & 21.8 \\
\hline Severe $(61-80 \mathrm{~dB})$ & 12 & 9 \\
\hline Profound (deaf) $(81+\mathrm{dB})$ & 92 & 69.2 \\
\hline Cause & \# of diagnoses* & $\%$ \\
\hline Sensorineural congenital & 86 & 30.7 \\
\hline Sensorineural acquired & 68 & 24.3 \\
\hline Wax & 4 & 1.4 \\
\hline Foreign Body & 1 & 0.4 \\
\hline Otitis Externa & 2 & 0.7 \\
\hline Acute Otitis Media & 8 & 2.9 \\
\hline Chronic Otitis Media & 45 & 16.1 \\
\hline Serous Otitis Media & 12 & 4.3 \\
\hline Other & 10 & 3.6 \\
\hline Cause not given & 44 & 15.7 \\
\hline *Diagnoses are by ear; multiple diagnoses permitted \\
\hline
\end{tabular}

Visual impairments

In total, 83 children had bilateral visual impairment (1.2 per 1000, 95\% Cl: 0.9-1.5). Most assessed children had profound visual impairment (logMar $>1.3,56.6 \%$ ) (Table 4). Cataract was the most common cause (33.9\%). In $22.0 \%$ of cases, the paediatrician was unable to provide a diagnosis.

452 children were identified during the screening as needing to take the vision assessment, but only 260 completed the assessment. Children who did not complete the vision assessment often had intellectual impairments ( $n=176,92 \%$ of children not completing vision assessment). 
Table 4

Severity and causes of visual impairment

\begin{tabular}{|lll|}
\hline Severity (logMar) & N of children & $\%$ \\
\hline Moderate $(\geq 0.5$ and $\leq 1)$ & 17 & 37.8 \\
\hline Severe $(>1$ and $\leq 1.3)$ & 0 & 0 \\
\hline Profound (blind) $(>1.3)$ & 28 & 62.2 \\
\hline Causes & N of diagnosis* & $\%$ \\
\hline Refractive Error & 11 & 12.2 \\
\hline Cataract & 30 & 33.3 \\
\hline Aphakia & 2 & 2.2 \\
\hline Surgical & 1 & 1.1 \\
\hline Other Corneal Scar & 2 & 2.2 \\
\hline Globe Abnormality & 2 & 2.2 \\
\hline Cortical Blind & 12 & 13.3 \\
\hline Other & 10 & 11.1 \\
\hline Unknown & 20 & 22.2 \\
\hline *Multiple diagnoses permitted & \\
\hline
\end{tabular}

Intellectual impairments

Intellectual impairments were the most prevalent type of impairment/health condition assessed, with a prevalence of 6.5 children per 1000 (95\% Cl: 5.9-7.1). In most cases, paediatricians could not provide a specific diagnosis of the underlying health condition and all diagnoses provided were based on their professional opinion rather than by formal assessment. The most common types of diagnoses for intellectual impairment included conditions linked to cerebral palsy $(n=40,11.8 \%)$, Down syndrome $(n=6,1.8 \%)$, or linked to hypoxia from epilepsy $(n=22,6.5 \%)$.

Epilepsy, albinism and emotional distress

Prevalence of epilepsy and albinism were 1.9 per 1000 children (95\% Cl:1.6-2.2) and 0.1 per 1000 children (95\% Cl: $0.0-0.2$ ), respectively. Prevalence of emotional distress (symptoms of depression and post-traumatic stress) was 0.6 per 1000 children $(95 \% \mathrm{Cl}: 0.4-0.8)$.

Multiple impairments

Overall, $236(39.5 \%)$ of children with disabilities had multiple impairments. Amongst children with multiple impairments, $69.9 \%$ had two impairments, $22.5 \%$ had 3 impairments and $7.6 \%$ had 4 or more impairments. Children with emotional distress were most likely to have other impairments $(83.9 \%)$, followed by children with epilepsy (69.0\%).

Attributed causes and health seeking 
Caregivers of children with disabilities primarily attributed their child's impairment/health condition to biomedical causes (e.g. genetic, illness, trauma), although slightly over $10 \%$ felt their child's impairment was due to supernatural causes (Table 5). Many children had never been to see a health professional for their impairment/health condition, with health seeking ranging from $67.2 \%$ for children with physical impairments to $40.0 \%$ for children with visual impairments. For children for whom medical advice had been sought, less than a third of caregivers found that the services received were helpful. The most common reason for not seeking health services was due to a belief that the services would not be helpful, which was reported by approximately two-thirds of caregivers. The second most common reason across impairment types was due to prohibitive costs.

Table 5

Attributed causes of disability and health-seeking behaviours

\begin{tabular}{|c|c|c|c|c|c|c|c|c|c|c|c|c|}
\hline & \multicolumn{2}{|c|}{$\begin{array}{l}\text { Emotional } \\
(n=31)\end{array}$} & \multicolumn{2}{|c|}{$\begin{array}{l}\text { Physical (n } \\
=253)\end{array}$} & \multicolumn{2}{|c|}{$\begin{array}{l}\text { Visual ( } \\
=43)\end{array}$} & \multicolumn{2}{|c|}{$\begin{array}{l}\text { Hearing } \\
(n=133)\end{array}$} & \multicolumn{2}{|c|}{$\begin{array}{l}\text { Cognitive } \\
(\mathrm{n}=338)\end{array}$} & \multicolumn{2}{|c|}{$\begin{array}{l}\text { Epilepsy } \\
(\mathrm{n}=64)\end{array}$} \\
\hline & $\mathrm{n}$ & $\%$ & $\mathbf{n}$ & $\%$ & $\mathbf{n}$ & $\%$ & $\mathbf{n}$ & $\%$ & $\mathrm{n}$ & $\%$ & $\mathrm{n}$ & $\%$ \\
\hline \multicolumn{13}{|l|}{ Attributed causes } \\
\hline $\begin{array}{l}\text { Genetic/born } \\
\text { this way }\end{array}$ & 10 & 32.3 & 103 & 40.7 & 20 & 46.5 & 30 & 22.6 & 171 & 50.6 & 16 & 25 \\
\hline From trauma/ injury & 3 & 9.7 & 19 & 7.5 & 0 & 0 & 0 & 0 & 9 & 2.7 & 2 & 3.1 \\
\hline From illness & 12 & 38.7 & 97 & 38.3 & 10 & 23.3 & 74 & 55.6 & 110 & 32.5 & 32 & 50 \\
\hline Act of God/ supernatural & 4 & 12.9 & 28 & 11.1 & 8 & 18.6 & 19 & 14.3 & 41 & 12.1 & 12 & 18.8 \\
\hline Other & 0 & 0 & 2 & 0.8 & 0 & 0 & 4 & 3 & 0 & 0 & 0 & 0 \\
\hline Unknown & 2 & 6.5 & 4 & 1.6 & 5 & 11.6 & 6 & 4.5 & 7 & 2.1 & 2 & 3.1 \\
\hline \multicolumn{13}{|l|}{ Health seeking } \\
\hline Has seen medical doctor & 19 & 61.3 & 170 & 67.2 & 18 & 40.0 & 55 & 41.4 & 155 & 45.9 & 45 & 45.0 \\
\hline Medical services helpful* & 5 & 26.3 & 53 & 31.2 & 4 & 22.2 & 20 & 36.4 & 40 & 25.8 & 19 & 42.2 \\
\hline \multicolumn{13}{|c|}{ Reasons for not seeking medical advice ${ }^{\star \star}$} \\
\hline Do not need/Not useful & 8 & 66.7 & 60 & 72.3 & 15 & 0.6 & 54 & 69.2 & 132 & 72.1 & 16 & 84.2 \\
\hline Too expensive & 0 & 0 & 28 & 33.7 & 10 & 0.4 & 25 & 32.1 & 62 & 33.9 & 4 & 21.1 \\
\hline Services not available & 1 & 8.3 & 1 & 1.2 & 0 & 0 & 2 & 2.6 & 4 & 2.2 & 0 & 0 \\
\hline Too far/no transportation & 0 & 0 & 13 & 15.7 & 1 & 0 & 5 & 6.4 & 20 & 10.9 & 3 & 15.8 \\
\hline No time & 0 & 0 & 1 & 1.2 & 0 & 0 & 1 & 1.3 & 2 & 1.1 & 0 & 0 \\
\hline Do not know where to go & 2 & 16.7 & 6 & 7.2 & 2 & 0.1 & 3 & 3.8 & 20 & 10.9 & 2 & 10.5 \\
\hline Other & 1 & 8.3 & 1 & 1.2 & 0 & 0 & 1 & 1.3 & 2 & 1.1 & 0 & 0 \\
\hline
\end{tabular}


This is the first KIM used to estimate the prevalence and causes of disability in western Africa. Overall, 597 children were identified as having an eligible impairment/health condition, giving a prevalence of disability of 11.4 per 1000 (95\% Cl: 10.6-12.2) amongst children 7-16 years. This study captured data on both impairments (clinical assessments) as well as functioning (Washington Group-UNICEF Child Module screening), which is in line with the definition of disability described in the ICF.

The prevalence estimates found in this area of Niger are similar to other KIM studies. For example, prevalence of disability in children under 18 was 17.3 per 1000 in Malawi (95\% Cl: 16.9-17.7 per 1000) and 7.5 per 1000 (95\% Cl: 6.6-8.3 per 1000) for children under 10 in Kenya $[8,9]$. These KIM studies covered similar impairments/health conditions as in this Niger study, although they did not include albinism and emotional distress. A KIM study in Bangladesh found a prevalence of 9 per 1000 (95\% Cl: 8.7-9.4 per 1000) for children under 18, but the study focused on visual, hearing and physical impairments only.

Estimates of prevalence using the KIM method are generally slightly lower than in household surveys using other methodologies for assessing disability. For example, the Washington Group-UNICEF module on Child Functioning used in this study as a preliminary screening tool has been used on its own to generate estimates of disability in population-based surveys. Prevalence of disability (using the cut-off of "a lot of difficulty" in at least one domain) in children 2-17 has been estimated at 2.6\% (1.8-3.6\%) in north-western Cameroon [26], 2.3\% (1.4-3.7\%) in Telangana state, India [26], 3.3\% (2.6-4.3\%) in the Maldives [27] and 4.7 (4.0-5.4\%) in Guatemala [28]. In children 5-17 years, prevalence has been measured as 1.5 (1.0-1.7\%) in Vanuatu [29] and 1.5\% (1.0-2.1\%) in Nepal [30], which covers a similar age range as in this study and are similar to the estimates produced from this KIM. In contrast to KIMs, these other studies focus only on functioning and do not include data on the presence of clinical impairments, which can be important for planning health services. Previous studies also indicate that people with self-reported functional difficulties do not always necessarily have underlying clinical impairment [31].

This study also involved new innovations to the KIM. Other KIMs have used screening camps with specialists (e.g. physiotherapists, ophthalmologists, ENT doctors), while this study used paediatricians who visited KI identified children in or near their homes. This change resulted in a significant improvement in response rates, as in this study $85.6 \%$ of children identified by KIs were successfully examined by paediatricians, compared to $48 \%$ followup for screening camps [8]. However, paediatricians faced more challenges in undertaking certain assessments (e.g. visual and hearing impairment in children with intellectual impairments) or providing diagnoses for some conditions. Future KIMs may wish trial combinations of the two strategies, with paediatricians performing the initial assessment but with referral pathways in place to assess more complex cases. Even with diagnoses of impairments, additional research on the underlying causes of

The results of this study carry implications for the design and delivery of services. In this study, many children with disabilities had never sought medical attention for their impairment/health condition and amongst those that did, few found the services to be helpful. In Niger and many other countries, there are severe shortages of health and social services required for the management of the impairments. For example, there are only 20 ophthalmologists (1.0 per million population) in all of Niger (well below the World Health Organization's recommended minimum of 4.0 per million population) [32], and 0.02 child psychiatrists per 100,000 population [33]. Across low- and middleincome countries, there are also significant gaps in the availability of and access to rehabilitation providers, medications for epilepsy and psychiatric conditions, specialists in disability-related health services (e.g. audiologists, occupational therapists) and assistive products, and the limited services available tend to be heavily centralised $[34,35]$. Further, there is a need for broader inclusive planning to support the participation of children 
with disabilities. For example, there are severe shortages of inclusive education specialists and resources globally, which contributes to the high proportion of children with disabilities out of school or excluded from the learning process while in school $[36,37]$. The lack of access to needed health services and devices, combined with the lack of disability-inclusive planning (e.g. in infrastructure, schooling, transportation), means that most children with impairments will experience decreased functioning and participation (and thus disability).

\section{Limitations And Areas For Further Research}

Several limitations should be taken into account when interpreting the results of this study.

First, the KIM is designed to identify children with moderate/severe disabilities. Children with milder impairments are not intended to be captured through this method, which should be considered when interpreting and comparing prevalence estimate from this study to others using different methodologies.

Second, even among children with moderate/severe impairments, underreporting is likely. It is possible that Kls did not identify all eligible in their community, which would affect prevalence estimates. For example, boys were more likely to be identified by KIs ( $60 \%$ of children listed were male), which may reflect greater visibility of boys in the community and potential underreporting for girls. The prevalence of disability, however, was slightly higher amongst girls compared to boys, which may indicate less specific identification of boys amongst Kls. Additionally, most children with visual and hearing impairments had a profound severity, suggesting underreporting of children with moderate sensory impairments, which has been noted in other KIM studies [11]. It was also not possible to conduct visual and hearing assessments using the available assessment tools in many children with intellectual impairments due to challenges understanding and following the test instructions. However, estimates of visual and hearing impairment were adjusted to account for this non-response. Additionally, using the KIM for measuring emotional distress has not been validated; given that emotional distress is often an "invisible" disability, it is likely that prevalence is an underestimate.

Finally, paediatricians were not able to provide diagnoses for all impairments, particularly intellectual impairments. Further research involving specialists and more advanced equipment/testing materials will be needed to provide definitive diagnoses in many cases. Additionally, although not the focus of this study, research to understand the more distal causes of health conditions that lead to impairments (e.g. malnutrition) could identify for pathways for prevention. For example, iodine deficiency is a major cause of intellectual impairment globally and can be prevented through successful salt iodisation programmes [38].

Given these limitations, the figures presented in this paper should be interpreted as minimum likely estimates of prevalence and causes of the listed impairments/health conditions.

\section{Conclusion}

This study is the first use of the KIM in western Africa to estimate the prevalence of childhood disability. The KIM identified a large number of children with disabilities, many of whom had unmet needs for health services. Increased investment in health, rehabilitation and other services (e.g. inclusive education) are required to support the functioning, well-being and participation of children with disabilities.

\section{Declarations}


Ethical approval and consent to participate: The study received ethical approval from Le Comité National Éthique pour la Recherche en Santé [National Ethics Committee for Health Research] in Niger. Informed consent was obtained from the caregivers/guardians/parents of the study participants. Children provided assent. The study protocols were in line with national guidelines in Niger and internationally (e.g. Declaration of Helsinki).

Consent for publication: Not applicable

Availability of data and materials: The datasets generated and/or analysed during the current study are not publicly available as participants did not give their consent for their data to be uploaded onto a public repository but are available from the corresponding author on reasonable request.

Competing interests: The authors declare that they have no competing interests.

Funding: This research was funded by the Norwegian Research Council under the project "Addressing Local Barriers to Inclusive Education for Children with a Disability in the Sahel" (project No: 82424).

Authors' contributions: LMB developed the methodology and data collection tools, and wrote the main manuscript text. JL conducted the analyses and developed the data collection tools. AB and AKS led data collection. AG and AK secured funding and developed the methodology. IM contributed to the methodology. DF and RD provided critical feedback to the manuscript draft. All authors reviewed the manuscript.

Acknowledgements: We thank the enumerators for their tireless work and the research participants for their time, without which this research would not be possible.

\section{References}

1. Mactaggart I. Measuring disability in population-based surveys: the relationship between clinical impairments, self-reported functional limitations and equal opportunities in two low and middle income country settings: London School of Hygiene \& Tropical Medicine; 2018.

2. World Health Organization \& World Bank. World report on disability: World Health Organization; 2011.

3. Mathers C. The global burden of disease: 2004 update: World Health Organization; 2008.

4. United Nations Convention on the Rights of Persons with Disabilities, (2006).

5. World Health Organization. International Classification of Functioning, Disability and Health: ICF: World Health Organization; 2001.

6. United Nations. Convention on the Rights of Persons with Disabilities (CRPD) 2019. Available from: https://www.un.org/development/desa/disabilities/convention-on-the-rights-of-persons-with-disabilities.html.

7. United Nations. Transforming our world: The 2030 agenda for sustainable development. General Assembley 70 session. 2015.

8. Tataryn M, Polack S, Chokotho L, Mulwafu W, Kayange P, Banks LM, et al. Childhood disability in Malawi: a population based assessment using the key informant method. BMC pediatrics. 2017;17(1):198.

9. Kuper H, Nyapera V, Evans J, Munyendo D, Zuurmond M, Frison S, et al. Malnutrition and childhood disability in Turkana, Kenya: Results from a case-control study. PloS one. 2015;10(12).

10. Pal DK, Das T, Sengupta S. Comparison of key informant and survey methods for ascertainment of childhood epilepsy in West Bengal, India. International journal of epidemiology. 1998;27(4):672-6. 
11. Murthy GV, Mactaggart I, Mohammad M, Islam J, Noe C, Khan Al, et al. Assessing the prevalence of sensory and motor impairments in childhood in Bangladesh using key informants. Archives of disease in childhood. 2014;99(12):1103-8.

12. World Bank. World Bank Country and Lending Groups 2020. Available from: https://datahelpdesk.worldbank.org/knowledgebase/articles/906519.

13. United Nations Development Programme. Human Development Report 2019. New York, NY: UNDP, 2019.

14. Government of Niger. Rapport sur la situation socioéconomique des personnes handicapées [report on the socioeconomic situation of people with disabilities]. In: Statistique INdl, editor. Niamey, Niger2011.

15. Loeb ME, Eide AH, Mont D. Approaching the measurement of disability prevalence: the case of Zambia. ALTER-European Journal of Disability Research/Revue Européenne de Recherche sur le Handicap. 2008;2(1):32-43.

16. Bedford J, Mackey S, Parvin A, Muhit M, Murthy G. Reasons for non-uptake of referral: Children with disabilities identified through the Key Informant Method in Bangladesh. Disability and rehabilitation. 2013;35(25):2164-70.

17. Washington Group on Disability Statistics, UNICEF. Child Functioning for Children Age 5 to 17. 2016.

18. Simeonsson RJ, Leonardi M, Lollar D, Bjorck-Akesson E, Hollenweger J, Martinuzzi A. Applying the International Classification of Functioning, Disability and Health (ICF) to measure childhood disability. Disability and rehabilitation. 2003;25(11-12):602-10.

19. Johnson JG, Harris ES, Spitzer RL, Williams JB. The patient health questionnaire for adolescents: validation of an instrument for the assessment of mental disorders among adolescent primary care patients. Journal of Adolescent Health. 2002;30(3):196-204.

20. Perrin S, Meiser-Stedman R, Smith P. The Children's Revised Impact of Event Scale (CRIES): Validity as a screening instrument for PTSD. Behavioural and Cognitive Psychotherapy. 2005;33(4):487-98.

21. Dyregrov A, Yule W, editors. Screening measures: The development of the UNICEF screening battery. annual meeting of the International Society for Traumatic Stress Studies, Boston, MA; 1995.

22. United Nations. Population Dynamics 2019. Available from: https://population.un.org/wpp/Download/SpecialAggregates/Geographical/.

23. GOvernment of Niger. Recensement Général de la Population et de l'Habitat de 2012 [Niger Population and Housing Census 2012]. In: (Niger) NloS, editor. 2012.

24. Government of Niger. Indicateurs Économiques [Economic Indicators] Niamey, Niger2018 [cited 2020 October 8]. Available from: http://www.stat-niger.org/.

25. Mathenge W, Kuper H, Limburg H, Polack S, Onyango O, Nyaga G, et al. Rapid assessment of avoidable blindness in Nakuru district, Kenya. Ophthalmology. 2007;114(3):599-605.

26. Mactaggart I, Kuper H, Murthy G, Oye J, Polack S. Measuring disability in population based surveys: the interrelationship between clinical impairments and reported functional limitations in Cameroon and India. PloS one. 2016;11(10).

27. Banks LM, Hameed S, Kawsar Usman S, Kuper H. No One Left Behind? Comparing Poverty and Deprivation between People with and without Disabilities in the Maldives. Sustainability. 2020;12(5):2066.

28. International Centre for Evidence in Disability. Guatemala National Disability Study (Endis 2016) Main Report. London, UK: London School of Hygiene \& Tropical Medicine, 2017. 
29. International Centre for Evidence in Disability. Water, Women and Disability Study. Lonon, UK: London School of Hygiene \& Tropical Medicine, 2020.

30. Banks LM, Walsham M, Neupane S, Neupane S, Pradhananga Y, Maharjan M, et al. Access to Social Protection Among People with Disabilities: Mixed Methods Research from Tanahun, Nepal. The European Journal of Development Research. 2019:1-28.

31. Mactaggart I, Kuper H, Murthy G, Oye J, Polack S. Measuring disability in population based surveys: the interrelationship between clinical impairments and reported functional limitations in Cameroon and India. PloS one. 2016;11(10):e0164470.

32. Resnikoff S, Lansingh VC, Washburn L, Felch W, Gauthier T-M, Taylor HR, et al. Estimated number of ophthalmologists worldwide (International Council of Ophthalmology update): will we meet the needs? British Journal of Ophthalmology. 2020;104(4):588-92.

33. World Health Organization. Mental Health ATLAS 2017 Member State Profile: Niger 2017 [cited 2020 December 18]. Available from: https://www.who.int/mental_health/evidence/atlas/profiles-2017/NER.pdf? ua $=1$.

34. Bright T, Wallace S, Kuper H. A Systematic Review of Access to Rehabilitation for People with Disabilities in Low-and Middle-Income Countries. International journal of environmental research and public health. 2018;15(10):2165.

35. Meyer A-C, Dua T, Ma J, Saxena S, Birbeck G. Global disparities in the epilepsy treatment gap: a systematic review. Bulletin of the World Health Organization. 2010;88:260-6.

36. Banks LM, Zuurmond M, Monteath-Van Dok A, Gallinetti J, Singal N. Perspectives of children with disabilities and their guardians on factors affecting inclusion in education in rural Nepal:"I feel sad that I can't go to school”. Oxford Development Studies. 2019;47(3):289-303.

37. Kuper H, Monteath-van Dok A, Wing K, Danquah L, Evans J, Zuurmond M, et al. The impact of disability on the lives of children; cross-sectional data including 8,900 children with disabilities and 898,834 children without disabilities across 30 countries. PloS one. 2014;9(9):e107300.

38. Sadou H, G Dandano I, M Alma M, Daouda H. lodine deficiency disorders after sixteen years of universal dietary salt iodization in a severe iodine deficiency village in Niger. The Open Nutrition Journal. 2014;8(1).

\section{Figures}




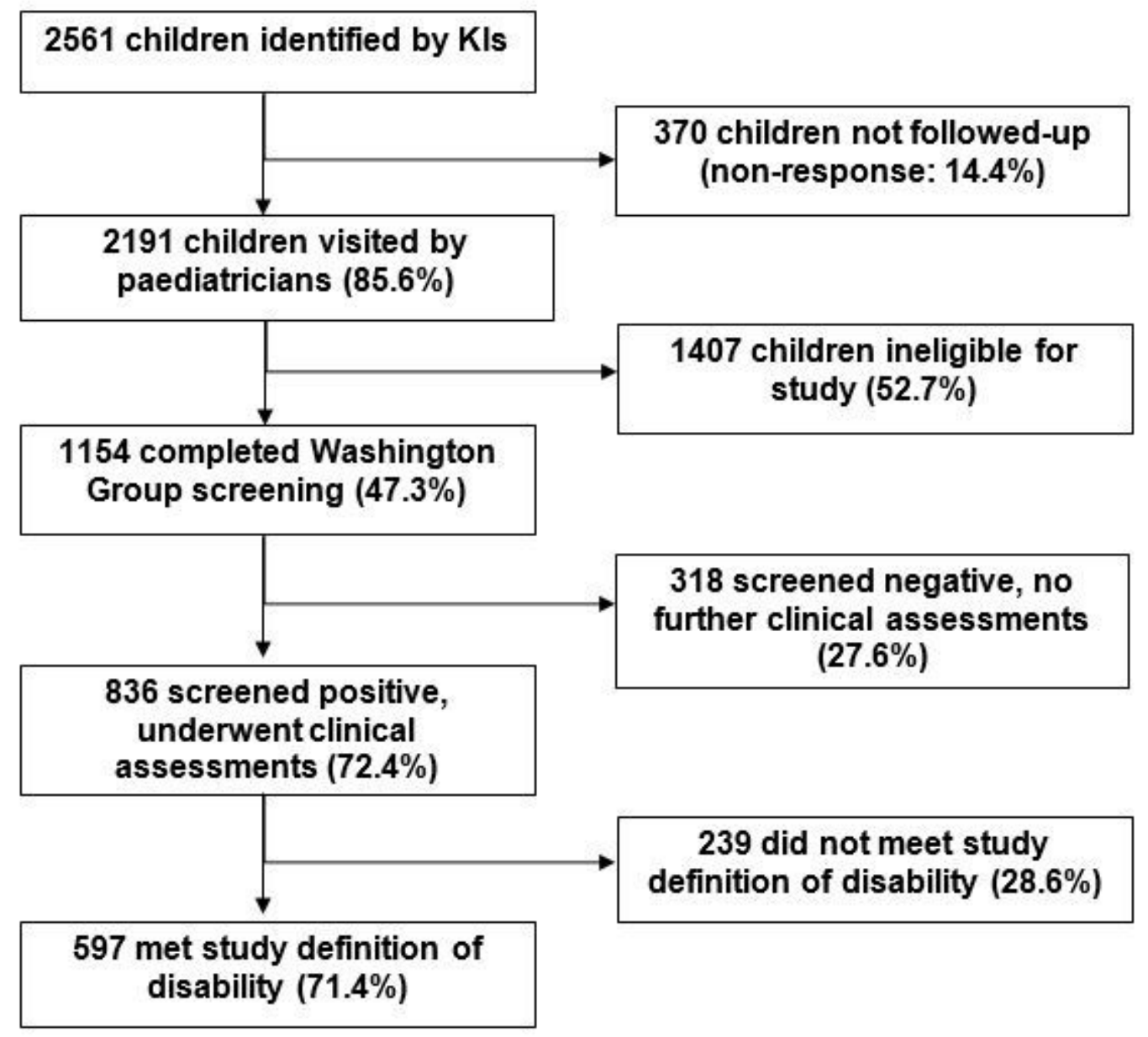

Figure 1

Flow chart of children identified and assessed

\section{Supplementary Files}

This is a list of supplementary files associated with this preprint. Click to download.

- Tables1.docx 